\title{
O sistema multiportas de resolução de conflitos e os serviços notariais: uma análise sobre sua aplicação aos tabelionatos de protestos
}

Horácio Monteschio ${ }^{1}$

\section{Resumo}

É incontroverso que o Poder Judiciário vem permitindo e adotando formas alternativas à jurisdição para a composição dos conflitos de interesses. No mesmo pensar, tem sido muito exitosa e profícua a sinergia produzida entre os notários e registradores e o Poder Judiciário, ainda mais com as inovações legislativas produzidas nos últimos anos. Em consonância com a eficiência dos serviços prestados o Conselho Nacional de Justiça tem assumido postura a incrementar os meios e as matérias colocados à disposição para a solução dos conflitos servindo-se dos serviços notariais e registrais. Como tônica do presente texto e fazendo referência ao Provimento do Conselho Nacional de Justiça ${ }^{\circ} 72$, dispondo sobre medidas de incentivo à quitação ou à renegociação de dívidas protestadas nos tabelionatos de protesto do Brasil, o presente trabalho destaca a importância do sistema multiportas para solução dos conflitos. Serve-se do método dedutivo e de revisão bibliográfico e conclui pela eficiência dos serviços prestados pelos registradores e notários no Brasil.

Palavras-chave: Serviços notariais; Sistema multiportas; Meios alternativos; Tabelionatos de protestos.

\footnotetext{
${ }^{1}$ Pós-Doutor em Direitos Humanos pelo Ius Gentium Conimbrigae da Faculdade de Direito da Universidade de Coimbra-Portugal. Pós-Doutor em Direito das Relações Internacionais pela Universidade de Reggio CalabriaItália. Pós-Doutor pela UNICURITIBA, Doutor em Direito pela FADISP e Mestre em Direito da Personalidade pelo UNICESUMAR. É Professor do Programa de Mestrado em Direito da UNIPAR (PR) e do CERS (PE). Membro correspondente da Academia Paulista de Letras Jurídicas. Membro do Instituto dos Advogados do Paraná. Advogado.h.monteschio@uol.com.br
} 


\title{
The multiport system for dispute resolution |and notary services: an analysis on its application to protest tablionages
}

\begin{abstract}
It is undisputed that the Judiciary has been adopting alternative forms of jurisdiction for the composition of conflicts of interest. In the same way, the synergy produced between notaries and registrars and the Judiciary has been very successful and fruitful, especially with the legislative innovations produced in recent years. In line with the efficiency of the services provided, the National Council of Justice has taken a stance to increase the means and matters made available for the resolution of conflicts using notary and registry services. As the keynote of this text and referring to the Provision of the National Council of Justice No. 72, providing for measures to encourage the discharge or renegotiation of debts protested in the protest notaries of Brazil. The present work highlights the importance of the multiport system for conflict resolution. It serves as a deductive and bibliographic review method and concludes with the efficiency of the services provided by registrars and notaries in Brazil.
\end{abstract}

Keywords: Notary services; multiport system; alternative means of conflict resolution; protest notaries.

\section{INTRODUÇÃO}

O presente artigo tem como objetivo principal a análise atual quadro jurídico envolvendo os meios alternativos (ou adequados), para a solução dos conflitos de interesses. A pergunta que se pretende responde é: A inovação produzida pelo Provimento ${ }^{\circ} 72$ do Conselho Nacional de Justiça, o qual assegura a possiblidade dos Cartórios de protestos a realizarem audiência de concitação e mediação representa avanço normativo e facilitador na solução dos conflitos? A hipótese reside na pertinência da atuação dos notários de protestos, nesse contexto inovador, incorporado pelo Código de Processo Civil e as Resoluções do Conselho Nacional de Justiça. Por conseguinte, para uma melhor compreensão sobre a temática se utiliza de uma revisão bibliográfica e doutrinária adotando o método dedutivo. Os resultados alcançados, dentro da metodologia utilizada contemplam que havendo um número maior de possibilidades para os jurisdicionados de alcançarem seus objetivos, de modo reflexo haverá uma redução de demandas tramitando perante o Poder Judiciário.

As atividades notariais e de registro constituem em funções públicas no Brasil com fulcro no art. 236 da Constituição Federal, as quais não são executadas diretamente pelo Estado, mas por meio de delegação a particulares, "os notários e registradores, portanto, são profissionais do direito que exercem uma função pública delegada pelo Estado. Tais atividades 
são desempenhadas em caráter privado, sem que com isso tais profissionais venham a integrar o corpo orgânico do Estado"”2.

Ao regulamentar o art. 236 da Constituição Federal, a Lei $n^{\circ} 8.935$ de 18 de novembro de 1994, veio a reforçar a ideia da prestação de serviços feita na forma de delegação, impondo seu exercício a cargo de bacharéis em direito como regra, e para aqueles que estejam vinculados ao serviço notarial há mais de 10 anos. Para tanto, exige se aprovação em concurso público de provas títulos, cuja realização é feita pelo Poder Judiciário, contando com a participação da Ordem dos Advogados do Brasil e do Ministério Público.

Em nada se confunde a delegação das atividades notariais e registrais dos modelos de concessão ou permissão, pois se trata de atividade jurídica do Estado, na dicção do art. 236 da Constituição Federal, e não simplesmente de atividade material, cuja prestação é transferida para os particulares mediante uma relação contratual, através de concessão ou permissão.

Desta forma, a delegação feita ao notário ou registrador é feita à pessoa natural, sendo atividade estatal, de natureza pública, cujo ingresso se dá por concurso público de provas e títulos, não por adjudicação em processo licitatório, sendo os seus titulares, fiscalizados pelo Poder Judiciário Estadual, não sendo, porém, servidores públicos e tampouco ocupando cargo público.

Em razão da própria história da formação do Estado brasileiro, no qual em um primeiro momento era atribuição dos "registros paroquiais" o registro dos imóveis, posteriormente, com o desenvolvimento essa atribuição passou a ser prestado pelo Estado. Com a presença religiosa e do Estado, em face à importância do direito de propriedade a atividade notarial e registral assumiu contornos de "capilaridade nacional", sendo inegável a transferência para o Estado da atividade registral e notarial.

Paralelamente ao aspecto da capilaridade, as a atividades prestadas pelos registradores e notários tem o intuito de desonerar e auxiliar a prestação de um serviço relevante a todos os brasileiros. Ademais disso, existem atos que são prestados por notários e registradores em caráter gratuito, os quais são garantidores da cidadania e dos direitos da personalidade, bem como em alguns casos, registre-se, os inventários e divórcios acabaram por impor um novo regime procedimental no Brasil, que prestigia a agilidade e a desburocratização.

Neste pensar, de impor um novo contorno ao acesso a justiça, cabe ressaltar as "ondas" de reforma consagradas na doutrina de Mauro Cappelletti e Bryant Garth:

Podemos afirmar que a primeira solução para o acesso - a primeira "onda" desse movimento novo - foi a assistência judiciária; a segunda dizia respeito às reformas tendentes a proporcionar representação jurídica para os interesses "difusos",

\footnotetext{
${ }^{2}$ LOUREIRO, Luiz Guilherme. Registros públicos. Rio de Janeiro: Forense; São Paulo: Método, 2014, p. 1.
} 
especialmente nas áreas da proteção ambiental e do consumidor; e o terceiro - e mais recente - é o que nos propomos a chamar simplesmente "enfoque de acesso à justiça" porque inclui os posicionamentos anteriores, mas vai muito além deles, representando, dessa forma, uma tentativa de atacar as barreiras ao acesso de modo mais articulado e compreensivo. ${ }^{3}$

Ao fazer referência as ondas de acesso à Justiça Kim Economides, leciona a presença e importância da terceira onda a qual está por ganhar cada vez mais espaço. Desse modo, alude que a terceira onda defendida por Mauro Cappelletti e Bryant Garth:

\begin{abstract}
refere-se à assistência jurídica, ou judicare; a segunda traduz-se pela justiça de interesse público (a articulação da representação de direitos coletivos mediante ações de classe e de interesse público); e, a terceira, conhecida hoje como "abordagem de acesso à justiça", inclui a justiça informal, o desvio de casos de competência do sistema formal legal e a simplificação da lei. ${ }^{4}$
\end{abstract}

Convergindo aos raciocínios até aqui expostos, mas servindo-se de outro enfoque, é justificável afirmar que os serviços prestados pelos notários e registradores estão presentes em praticamente todos os 5.570 Municípios do Brasil, comprovando a presença do Estado brasileiro em toda extensão continental brasileira, oportunizando experiências positivas e enriquecedoras tanto ao Poder Público, quanto aos particulares, nas práticas cotidianas em um mundo impulsionado em conexões cibernéticas, cujas necessidades dos cidadãos tornam-se cada vez mais urgentes.

De outra banda, os que pensam de forma diferente centram suas críticas aos serviços prestados pelos notários e registradores sob o enfoque do elevado custo dos serviços prestados. Sob a nossa ótica, sem razão tal posicionamento pelo fato de que a desburocratização e agilidade empregadas pelos notários e registradores representam um dos seus principais predicados. Ademais, as custas e honorários dos notários são fixados por lei, que por sua vez são elaboradas pelos legisladores, e, portanto, dentro de um ambiente democrático. Além disso, os serviços delegados são fiscalizados pelo Poder Judiciário.

Sobreleva enfatizar que os serviços notários implicam na desoneração dos cofres públicos, pois, do contrário, o Estado deveria manter uma estrutura especializada para prestação destes serviços, ampliando a "máquina administrativa" e o "custo Brasil”. Por derradeiro, em razão das vicissitudes brasileiras, os serviços prestados pelos notários e registradores, pelo atual sistema, ficam imunes às pressões políticas, em face da fiscalização feita pelo Poder Judiciário.

Neste sentido, cabe pinçar os dados coletados pela Agência Brasil: o Poder Público economizou mais de quatro bilhões de reais com a delegação às serventias extrajudiciais dos processos de divórcio e inventário:

\footnotetext{
${ }^{3}$ CAPPELLETTI, Mauro; GARTH, Bryant. Acesso à Justiça. Tradução de Ellen Gracie Northfleet. Porto Alegre: Fabris, 1988 p. 31.

${ }^{4}$ ECONOMIDES, Kim. Lendo as ondas do "Movimento de Acesso à Justiça": epistemologia versus metodologia? In: CIDADANIA, JUSTIÇA E VIOLÊNCIA, Organizadores Dulce Pandolfi... [et al]. Rio de Janeiro: Ed. Fundação Getúlio Vargas, 1999. 248p. p. 71.
} 


\begin{abstract}
Desde que foi aprovada, em 2007, a lei que autorizou que separações e divórcios consensuais podem ser feitos em processos extrajudiciais, os cartórios brasileiros fizeram mais de 2 milhões de escrituras. Processos que antes iriam parar em tribunais. Segundo cálculos do Colégio Notarial do Brasil, a mudança significou uma economia de cerca de R\$ 4 bilhões para o Sistema Judiciário. ${ }^{5}$
\end{abstract}

Os dados mais atualizados, com toda certeza devem expressar cifras muito maiores e representam uma maior economia ao Estado brasileiro. Como se verá em linhas a seguir, a convergência de forças e interesses entre a desjudicialização e o "sistema multiportas" somente tem produzido efeitos favoráveis e de desenvolvimento. No caso vertente, a atuação feita pelos cartórios de protestos, por igual, se apresenta como alternativa célere e útil a conjunção de forças entre o Poder Público e os delegatários do serviço público.

Neste sentido, vem a calhar a doutrina de Adriana Pereira Campos: "a desjudicialização não consiste no afastamento do Judiciário, mas a adequação às necessidades sociais atuais, de modo a promover outras formas de acesso à justiça por meio de métodos de tratamento de conflitos diversos". ${ }^{6}$

Feitas essas considerações iniciais, demonstra-se que o interesse do presente trabalho é tornar cada vez mais visível a importância do sistema multiportas para a solução dos conflitos de interesses, tendo como enfoque principal o serviço prestado pelos notários e registradores, especificamente, pelos cartórios de protesto. Ao final se conclui que os objetivos de credores em receber seus valores são alcançados e, aos devedores, dá-se uma oportunidade de conciliar e negociar os valores pretendidos fora do Poder Judiciário.

\title{
2 RESOLUÇÃO No 125 DO CONSELHO NACIONAL DE JUSTIÇA E O SISTEMA MULTIPORTAS
}

Dentro do processo de implantação de políticas públicas que busquem uma positivação e reconhecimento da terceira onda de acesso à Justiça, ou seja, das formas alternativas de solução de conflitos, o Conselho Nacional de Justiça (CNJ) vem exercendo um papel extremamente importante para essa consolidação. Além disso, o CNJ vem contribuindo decisivamente para a construção de um ambiente de promoção dessas formas consensuais e alternativas de resolução de conflitos. Para tanto, registre-se, por meio da publicação da Resolução no 125 de 29 de novembro de 2010, regulamentou, pela primeira vez, a mediação e conciliação em âmbito brasileiro, instituindo a chamada "Política Judiciária Nacional de Tratamento Adequado dos Conflitos de Interesses" no âmbito do Judiciário. Nas palavras de Gabbay (2011):

\footnotetext{
${ }^{5}$ ANOREG BR, 2018, on-line.

6 CAMPOS, Adriana Pereira. Mediação Escolar como Caminho para a Desjudicialização: Potencialidades. Argumentun, Marília, v. 19, n. 3, set./dez. 2018. p. 831.
} 
Nesse sentido, no Brasil o CNJ tem determinado que os órgãos judiciários ofereçam, além da solução adjudicada mediante sentenças dos juízes, mecanismos de resolução consensual de controvérsias entre as partes, bem como a prestação de atendimento e orientação aos cidadãos, incentivando a autocomposição de litígios e a pacificação social por meio da conciliação e mediação. ${ }^{7}$

Cabe ressaltar a importância da Resolução 125 do Conselho Nacional de Justiça, de 29 de novembro de 2010, a qual veio a dar contornos mais adequados e céleres para a solução de conflitos, como claro intuito de fomentar, no sistema jurídico procedimental brasileiro, um novo olhar sobre a solução dos conflitos de interesses denominado de "sistema multiportas" de resolução de controvérsias.

A fonte que serviu de inspiração ao sistema multiportas (ou tribunal multiportas) ao sistema brasileiro foi o norte-americano denominado de "Multi-door Courthouse System", o qual possui contornos de não impor formas restritivas para a solução de controvérsias exclusivamente ao Poder Judiciário.

A expressão "Sistema Multiportas de Justiça" (multidoor courthouse system) foi criada pelo Professor Frank Sander, da Escola de Direito da Universidade de Harvard, no ano de 1976, com o argumento de que com o conflito sendo tratado de forma adequada, será possível a utilização eficiente dos recursos pelos tribunais, reduzindo custos e tempo de um processo normal e, consequentemente, diminuindo a ocorrência de conflitos subsequentes, visto que o objetivo precípuo do sistema multiportas é a solução real da discordância causada pelo conflito. ${ }^{8}$

Como decorrência do "Multi-door Courthouse System", oferecem-se meios alternativos e, muitas vezes, mais adequados ao tipo de conflito, visando a solução, tais como: negociação, conciliação, mediação e arbitragem. Nas palavras de Luis Fernando Guerrero, o "sistema multiportas é uma tendência, não necessariamente nova, de se buscar formas de solução de conflitos que possam coexistir ou até mesmo fazer as vezes do tradicional sistema judicial de solução de conflitos. Essas formas podem ser realizadas a partir de uma postura amigável ou adversarial das partes."9

Ao adotar o "Multi-door Courthouse System" com o formato brasileiro a Resolução $\mathrm{n}^{\mathrm{o}} 125$ do Conselho Nacional de Justiça fixou suas premissas na possibilidade de ofertar ambiente adequado às partes envolvidas para tentarem a conciliação e mediação.

\footnotetext{
${ }^{7}$ GABBAY, Daniela Monteiro. Mediação \& Judiciário: Condições necessárias para a institucionalização dos meios autocompositivos de solução de conflitos. São Paulo: USP, 2011, 273 p. Tese (Doutorado) - Direito Processual, Faculdade de Direito da USP, São Paulo, 2011. p. 11.

${ }^{8}$ GIMENEZ, Charlise Paula Colet. A Justiça Consensual do Tribunal Múltiplas Portas e a Política Pública. NorteAmericana de Tratamento de Conflitos: Contribuições ao Modelo Brasileiro. In: Revista Opinião Jurídica, Fortaleza, n. 20, 2017. p. 84-111.

${ }^{9}$ GUERRERO, Luis Fernando. Efetividade das estipulações voltadas à instituição dos meios multiportas de solução de litígios. São Paulo: USP, 2012, 255 p. Tese (Doutorado) - Curso de Pós-Graduação da Faculdade de Direito da Universidade de São Paulo - Departamento de Direito Processual - DPC, São Paulo, 2012. 2012, p. 13.
} 
A exemplo do que ocorreu com a Lei da Arbitragem Lei $n^{\circ}$ 9.307/96, o sistema multiportas sofreu críticas ao argumento de violação ao art. $5^{\circ}, \mathrm{XXXV}$ da Constituição Federal (a lei não pode afastar a prestação da tutela jurisdicional). Tais críticas se mostraram açodadas e sem fundamento jurídico, em razão de que não se está afastando a prestação da tutela jurisdicional, mas sim, ofertando-se uma alternativa àquele que livre e espontaneamente assim o queira. Neste sentido, cabe ressaltar a posição de Fredie Didier Jr e Leonardo Carneiro da Cunha:

\begin{abstract}
Enquanto não for quebrada a ideologia estatal do ciclo vicioso recorrista, qualquer transformação que se faça, na tentativa de conter a sobrecarga de processos das Cortes Superiores, restará inoperante. o incentivo a métodos alternativos de resolução de controvérsias, tais como a mediação e a arbitragem, quando forem possíveis, ou ainda, o estímulo à solução de conflitos ainda na esfera administrativa

são algumas das saídas extrajurisdicionais viáveis, para além das reformas de descongestionamento apresentadas anteriormente. ${ }^{10}$
\end{abstract}

Destarte, tanto a arbitragem quando o sistema multiportas estão a prestar, com a sua presença no sistema normativo brasileiro, um grande serviço ao desenvolvimento e desburocratização do país.

Neste sentido, cabe ressaltar a doutrina formulada por Maria Tereza Aina Sadek, a qual se destaca que o Poder Judiciário não é a única porta de acesso à Justiça:

\begin{abstract}
O Poder Judiciário não possui o monopólio da efetivação dos direitos e da resolução de conflitos. Não é a única porta de acesso à justiça. Outros espaços têm se constituído para a garantia de direitos e para a solução de controvérsias. Dentre essas instituições, deve-se citar o Ministério Público, a Defensoria Pública, além das organizações erigidas a partir de princípios orientados pela pacificação, como a conciliação, a mediação e a arbitragem. ${ }^{11}$
\end{abstract}

Feitas essas considerações, o sistema multiportas veio para aprimorar, desburocratizar, tornar mais ágil a solução dos conflitos existentes em nossa sociedade. Não é a solução para todos os problemas, mas uma alternativa viável para desafogar o Poder Judiciário.

\title{
3 MEIOS ALTERNATIVOS NO CÓDIGo DE PROCESSO CIVIL BRASILEIRO
}

Uma das principais inovações introduzidas pelo Código de Processo Civil de 2015 consiste na possibilidade de as partes adotarem, para solução da controvérsia existente, meios alternativos. Cabe ressaltar que a destinação de um capítulo na legislação processual civil a

\footnotetext{
${ }^{10}$ DIDIER JR., Fredie; CUNHA, Leonardo Carneiro da. Julgamento de casos repetitivos. Salvador: Juspodivm, 2016. p. 403.

${ }^{11}$ SADEK, Maria Tereza Aina. Acesso à Justiça: um Direito e seus obstáculos. In: Revista USP, no 101 (maio), 2014, pp. 55-66.
} 
esses meios representa a possibilidade para os envolvidos em buscar a solução da pendência de forma mais célere e conveniente. Nestes termos leciona Daniel Amorim Assumpção Neves:

\begin{abstract}
A valorização das formas alternativas de solução dos conflitos já é demonstrada no art. $3^{\circ}$ do Código de Processo Civil. Nos termos do $\S 2^{\circ}$, o Estado promoverá, sempre que possível, a solução consensual dos conflitos, enquanto o $\S 3^{\circ}$ prevê que a conciliação, a mediação e outros métodos de solução consensual de conflitos deverão ser estimulados por juízes, advogados, defensores públicos e membros do Ministério Público, inclusive no curso do processo.

O Código de Processo Civil, entretanto, não trouxe apenas disposições principiológicas no que se refere as formas consensuais de solução dos conflitos. Há uma seção inteira de um capítulo destinada a regulamentar a atividade dos conciliadores e dos mediadores judiciais (arts. 165-175), inclusive fazendo expressamente a distinção entre conciliação e mediação. ${ }^{12}$
\end{abstract}

A mediação é forma alternativa de solução de conflitos fundada no exercício da vontade das partes, o que é suficiente para ser considerada espécie de forma consensual do conflito, mas não deve ser confundida com a autocomposição. Trata-se de uma das modalidades de solução de conflitos judicial ou extrajudicial, por essência informal, na qual partes envolvidas na disputa buscam o entendimento com ajuda de um terceiro neutro, que em momento algum propõe uma solução, apenas os ajuda de forma empática na facilitação do diálogo utilizando as técnicas de comunicação não violenta. Esta modalidade propicia o encontro das partes para que tratem das disputas e, conjuntamente, ofereçam possíveis encaminhamentos, pactuando de forma autônoma, com o objetivo de preservar os laços que as uniram. Sob esse enfoque da mediação é importante citar a doutrina de Rosemiro Pereira Leal:

\begin{abstract}
é nomeado um terceiro ou terceiros neutros, com o fito de pacificar a controvérsia de seus interesses particulares, ou seja, restabelecer a comunicação com a meta de encontrarem a solução da disputa, sem a intervenção do Estado. Trata-se de um procedimento em que as partes são verdadeiramente os protagonistas do processo. $\mathrm{O}$ mediador ou o co-mediador apenas auxiliam na restauração e sinalização caminhos para preservação dos laços de afetividade e respeito entre as partes. ${ }^{13}$
\end{abstract}

No mesmo sentido Juan Carlos Vezzulla assevera que a "mediação é uma técnica de resolução de conflitos não adversarial, que, sem imposições de sentenças ou de laudos e com um profissional devidamente formado, auxilia as partes a acharem seus verdadeiros interesses e a preservá-los num acordo criativo em que as duas partes ganhem. ${ }^{14}$

É imprescindível ressaltar que todas as afirmações e citações formuladas convergem para a admissibilidade e importância da presença de um terceiro desinteressado que tem como função a conciliação das partes. O que representa exatamente o pensamento de Luis Alberto Warat:

\footnotetext{
${ }^{12}$ NEVES, Daniel Amorim Assumpção. Manual de direito processual civil - volume único. Salvador: Juspodium, 2021, p. 381.

${ }^{13}$ LEAL, Rosemiro Pereira. Teoria geral do processo: primeiros estudos. 14 ed. Belo Horizonte: Fórum, 2018. p. 105.

${ }^{14}$ VEZZULA, Juan Carlos. Teoria e Prática da Mediação. Curitiba: IMAB, 1998.p. 16.
} 
Um processo de reconstrução simbólica do conflito, no qual as partes têm a oportunidade de resolver suas diferenças reinterpretando, no simbólico, o conflito com o auxílio de um mediador, que as ajuda, com sua escuta, interpretação e mecanismos de transferência, para que elas encontrem os caminhos de resolução, sem que o mediador participe da resolução ou influa em decisões ou mudanças de atitude (nisso se baseia sua imparcialidade, é imparcial porque não resolve nem decide)..$^{15}$

No presente caso, o delegatário do serviço público, em face da confiabilidade e da fé pública de que é detentor, perante a sociedade e garantida pela Constituição, somente vem a reforçar a possibilidade, dentro do serviço notarial de protesto, da prestação desse relevante serviço, ao facilitar o diálogo e a recolocação do conflito entre as partes em um cenário em que todos os entes ganham.

A primeira, e talvez, a principal diferença entre mediação e conciliação é a inexistência de sacrifício total ou parcial dos interesses das partes na crise jurídica. É nesse sentido a previsão de solução com "benefícios mútuos" presente no $\S 3^{\circ}$ do art. 165 do CPC. ${ }^{16}$

Para que seja possível uma solução consensual sem sacrifício de interesses, diferente do que ocorre na conciliação, a mediação não é centrada no conflito em si, mas sim em suas causas.

Diferente do conciliador, o mediador não propõe soluções do conflito às partes, mas as conduz a descobrirem as causas, de forma a possibilitar sua remoção e assim chegarem à solução do conflito. Portanto, as partes envolvidas chegam por si sós à solução consensual, tendo o mediador apenas a tarefa de induzi-las a tal ponto de chegada.

Por sua vez, o conciliador interfere na condução do processo propondo possíveis encaminhamentos/acordos entre as partes. Ressalta-se que a autonomia da vontade das partes aqui é também plenamente preservada, pois mesmo quando o conciliador ou coconciliador propõe uma solução esta ação constitui-se, como o próprio nome declara, uma "proposta", que jamais poderá ser imposta.

\footnotetext{
${ }^{15}$ WARAT, Luis Alberto. Em nome do acordo: a mediação no direito. Buenos Aires: Angra Impresiones, 1998. p. 31.

${ }^{16}$ Art. 165. Os tribunais criarão centros judiciários de solução consensual de conflitos, responsáveis pela realização de sessões e audiências de conciliação e mediação e pelo desenvolvimento de programas destinados a auxiliar, orientar e estimular a autocomposição.

$\S 1^{\circ}$ A composição e a organização dos centros serão definidas pelo respectivo tribunal, observadas as normas do Conselho Nacional de Justiça.

$\S 2^{\circ} \mathrm{O}$ conciliador, que atuará preferencialmente nos casos em que não houver vínculo anterior entre as partes, poderá sugerir soluções para o litígio, sendo vedada a utilização de qualquer tipo de constrangimento ou intimidação para que as partes conciliem.

$\S 3^{\circ} \mathrm{O}$ mediador, que atuará preferencialmente nos casos em que houver vínculo anterior entre as partes, auxiliará aos interessados a compreender as questões e os interesses em conflito, de modo que eles possam, pelo restabelecimento da comunicação, identificar, por si próprios, soluções consensuais que gerem benefícios mútuos.
} 
Nestes termos, para Pedro Calmon, a conciliação se constitui: "meio judicial ou extrajudicial de resolução de controvérsias no qual as partes envolvidas delegam a uma terceira pessoa (neutra), que terá como missão promover a aproximação das mesmas, bem como orientá-las na consecução de um acordo. O terceiro neutro - conciliador - tem como missão facilitar o diálogo entre as partes e seu possível acordo."17

De mesmo modo, vale ressaltar a análise referente ao tema, trazida por Daniela Monteiro Gabbay:

\begin{abstract}
A respeito da postura do terceiro imparcial frente à autonomia das partes, o conciliador pode assumir um lugar de poder, pois embora ele não tenha autoridade para impor uma decisão às partes, as técnicas de que se utiliza buscam conduzir as partes à realização do acordo. Essa situação é especialmente comum nas conciliações institucionais, como as que ocorrem no Judiciário, tanto nas sessões de conciliação dos juizados especiais quanto nas audiências de conciliação e julgamento presididas pelo juiz. ${ }^{18}$
\end{abstract}

Após essas considerações importantes, cabe relatar que a forma de resolução de conflitos nas sociedades perpassa pelo direito, a cultura e o ritual. Assim, para Oscar G. Chase,

Os processos de resolução de litígios são, em grande medida, um reflexo da cultura em que estão inseridos; não se trata de um sistema autônomo que seja, predominantemente, o produto de especialistas e experts isolados. Mais, eles são instituições através das quais a vida social e cultural é mantida, provocada e alterada, ou como a mesma ideia foi expressa, "constituída" ou "construída"."19

Desse modo, pode-se dizer que a conciliação é uma atividade mediadora direcionada ao acordo, qual seja, tem por objetivo central a obtenção de um acordo, com a particularidade de que o conciliador exerce leve ascendência hierárquica, pois toma iniciativas e apresenta sugestões, com vistas à conciliação. ${ }^{20}$

É relevante relembrar que o sistema multiportas e os meios alternativos só se justificam pelo fato de que quanto mais conflitos forem resolvidos fora da jurisdição, haverá menos processos a serem julgados pelo Poder Judiciário e, por consequência, esse Poder poderá funcionar de maneira mais célere e adequada nas causas em que foi infrutífera a conciliação e a mediação, tornando mais reais às aspirações do acesso à ordem jurídica justa. Nestes termos Valéria Lagrasta formula sua doutrina:

Uma forma de organização judiciária na qual o Poder Judiciário funciona como um centro de resolução de disputas, com vários e diversos procedimentos, cada qual com suas vantagens e desvantagens, que devem ser levadas em consideração, no momento

\footnotetext{
${ }^{17}$ CALMON, PETRÔNIO. Fundamentos da mediação e da conciliação, Rio de Janeiro: Forense, 2007. p. 143.

${ }^{18}$ GABBAY. Daniela Monteiro. Mediação \& Judiciário: condições necessárias para a institucionalização dos meios autocompositivos de solução de conflitos. Tese (Doutorado na área de Direito Processual) - Faculdade de Direito da Universidade de São Paulo, 2011. p. 49.

${ }^{19}$ CHASE, Oscar G. Direito, cultura e ritual: Sistemas de resolução de conflitos no contexto da cultura comparada. Tradução Sérgio Arenhart e Gustavo Osna. Editora Marcial Pons, São Paulo, 2014. (Coleção Processo e Direito). p. 21.

${ }^{20}$ VASCONCELOS, Carlos Eduardo. Mediação de Conflitos e Práticas Restaurativas. Rio de Janeiro: Forense; São Paulo: MÉTODO, 2017.p. 65.
} 
da escolha, em função das características específicas de cada conflito e das pessoas nele envolvidas. Em outras palavras, o sistema de uma única 'porta', que é a do processo judicial, é substituído por um sistema composto de vários tipos de procedimento, que integram um 'centro de resolução de disputas', organizado pelo Estado, comporto de pessoas treinadas para receber as partes e direcioná-las ao procedimento mais adequado para o seu tipo de conflito. ${ }^{21}$

O conciliador e o mediador em termos de atuação são equiparados. Há que destacar a exigência prevista no $\S 1^{\circ}$ do art. 167 do CPC. ${ }^{22}$ Registre-se que o art. 11 da Lei no 11.140/2015 cria um novo requisito não previsto no CPC: graduação há pelo menos dois anos em curso se ensino superior de instituição reconhecida pelo Ministério da Educação.

Não há necessidade dos conciliadores e mediadores serem advogados, o que deve ser saudado. As técnicas de conciliação e mediação não depende de conhecimentos jurídicos, sendo imprescindível que, além de operadores do Direito, outros profissionais, em especial aqueles acostumados a lidar com pessoas e conflitos entre eles, possam atuar como mediadores e conciliadores.

Desta forma, cabe aos notários e registradores, dentro da sua competência pessoal e profissional, as quais são eficientes, tornar o mais acessível possível a regra prevista no provimento 72 do Conselho Nacional de Justiça.

\section{PROVIMENTO N 72 DO CONSELHO NACIONAL DE JUSTIÇA}

Em 27 de junho de 2018, o Conselho Nacional de Justiça editou o Provimento do CNJ $\mathrm{n}^{\circ} 72$, o qual passou a dispor sobre medidas de incentivo à quitação ou à renegociação de dívidas protestadas nos tabelionatos de protesto do Brasil.

Neste sentido é imprescindível trazer o conceito extraído do próprio diploma legal que disciplina a matéria, ou seja, o art. $1^{\circ}$ da Lei ${ }^{\circ}$ 9.492/97:

Art. $1^{\circ} \mathrm{O}$ protesto é o ato formal e solene pelo qual se prova a inadimplência e o descumprimento de obrigação originada em títulos e outros documentos de dívida.

\footnotetext{
21 LUCHIARI, Valeria Feriolo Lagrasta. Histórico dos métodos alternativos de solução de conflitos. In: GROSMAN, Claudia Frankel; MANDELBAUM, Helena Gurfinkel (Org.). Mediação no judiciário: teoria na prática. São Paulo: Primavera Editorial, 2011, 283-320.

22 Art. 167. Os conciliadores, os mediadores e as câmaras privadas de conciliação e mediação serão inscritos em cadastro nacional e em cadastro de tribunal de justiça ou de tribunal regional federal, que manterá registro de profissionais habilitados, com indicação de sua área profissional.

$\S 1^{\circ}$ Preenchendo o requisito da capacitação mínima, por meio de curso realizado por entidade credenciada, conforme parâmetro curricular definido pelo Conselho Nacional de Justiça em conjunto com o Ministério da Justiça, o conciliador ou o mediador, com o respectivo certificado, poderá requerer sua inscrição no cadastro nacional e no cadastro de tribunal de justiça ou de tribunal regional federal.
} 
Destarte, o ato público e extrajudicial do protesto, o qual é feito por agente delegado que tem fé pública, ocorre quando uma pessoa física ou jurídica não cumpre o pagamento de um título no prazo estabelecido e o credor registra essa impontualidade em cartório.

Cabe destacar a Lei $\mathrm{n}^{\circ}$ 8.935/94, dispondo sobre serviços notariais e de registro, denominada simplesmente de "Lei dos cartórios", a qual regulamenta o art. 236 da Constituição Federal, quanto à competência do Tabelião de Protesto, em seu art. 11, consigna:

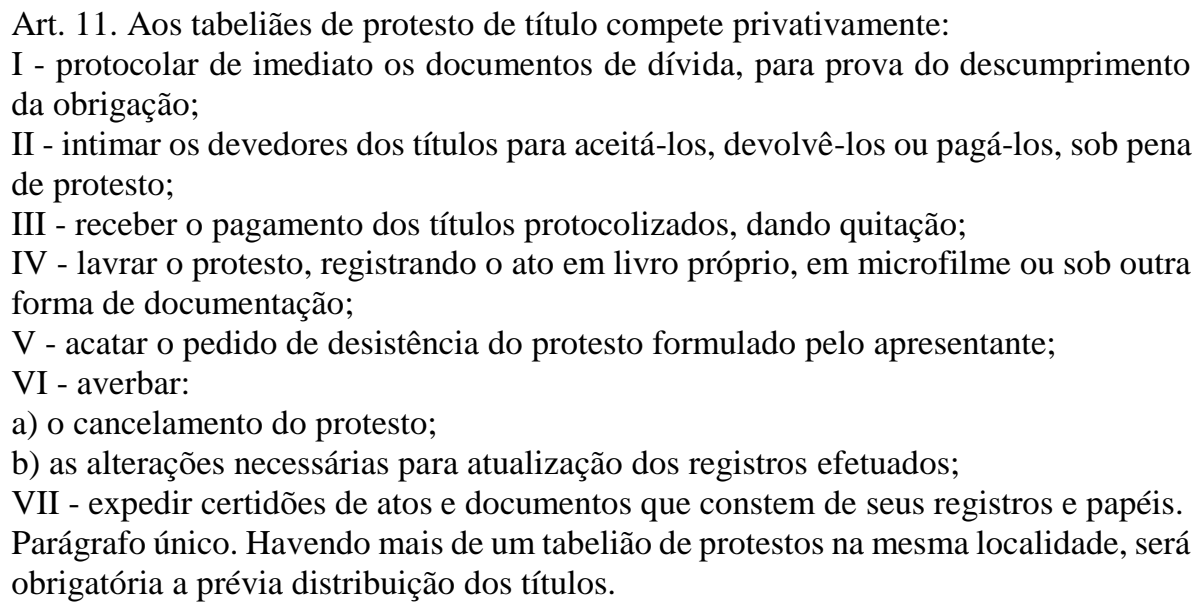

Em razão da não ausência, entre as atribuições dos tabeliães de protesto, a prática de Conciliação e Mediação é indispensável reiterar que o Conselho Nacional de Justiça é órgão competente para editar normas que regulamentem o serviço notarial, evidenciado no julgamento proferido pelo Supremo Tribunal Federal ao julgar o Mandado de Segurança 28.957/DF, da relatoria do Min. Teori Zavascki.

Uma das grandes vantagens do protesto de título é o fato dele possuir um elevado índice de recuperação de crédito. Aliando-se à possibilidade de conciliação e mediação, como vem descrito do Provimento 72 do Conselho Nacional de Justiça, possibilita-se que os já elevados índices de sucesso na recuperação do crédito sejam ainda mais ampliados. Segundo dados oficiais do IEPTB-SP, $60 \%$ dos títulos encaminhados a protesto são pagos em até cinco dias úteis. Ou seja, o serviço é rápido, fácil e econômico. ${ }^{23}$

Com a Mediação e Conciliação, com certeza serão ampliados esses percentuais, por que é possível às partes fixarem condições e termos para a resolução da controvérsia. Portanto, corrobora o que é aqui defendido de que os cartórios de protesto funcionam como um mecanismo indispensável para desafogar o Judiciário, pois contam com o respaldo da lei, sem necessitar da estrutura dos tribunais.

\footnotetext{
${ }^{23}$ https://jus.com.br/artigos/61864/tabelionato-de-protesto, acesso em 22 de out. 2021.
} 
Por sua vez, especificamente o art. 10 do Provimento $n^{\circ} 72$ do Conselho Nacional de Justiça, autorizou a designação de sessão de conciliação ou mediação, consagrando interessante e útil instrumento, aplicando-se as disposições previstas no Provimento do CNJ nº 67 de 2018. Nestes termos:

Art. 10. O credor ou o devedor poderão requerer a designação de sessão de conciliação ou de mediação, aplicando-se as disposições previstas no Provimento CN-CNJ n. 67/2018.

Dentro desse ambiente de ampla visão sobre os fatos e acontecimentos que vivenciamos há algum tempo, com a globalização, com os efeitos decorrentes da informática, com o acesso a justiça e a confirmação dos direitos fundamentais, e ainda, dentro de um enfoque transversal, deve-se buscar em searas fora dessas fronteiras a fundamentação para afastar os pensamentos que não convergem para a conciliação. Cita-se Zygmunt Bauman:

\begin{abstract}
A habilidade de que mais necessitamos para oferecer à esfera pública alguma chance de ressuscitação é a da interação com os outros - de manter um diálogo, de negociar, de obter a compreensão mútua e de administrar ou resolver os inevitáveis conflitos em qualquer instância da vida compartilhada. ${ }^{24}$
\end{abstract}

A experiência quotidiana dos advogados e a proximidade da Justiça cegam a profissão jurídica em relação a concepções mais profundas de justiça (interna ou social) e, consequentemente, fazem com que a profissão ignore a relação entre justiça civil e justiça cívica, "assim, indica importantes e novos desafios tanto para a responsabilidade profissional como para o ensino jurídico." 25

\title{
CONCLUSÕES
}

Como se buscou estabelecer no presente trabalho, destacar a eficiência e agilidade que se espera nos dias atuais em todas as áreas, os quais são denominados de "digitais", os meios de solução de controvérsias não podem ficar no formato analógico. Desta forma, guardando a devida congruência e simetria com que os serviços prestados pelos notários e registradores, o Conselho Nacional de Justiça tem assumido postura de vanguarda ao incrementar os meios e matérias colocados à disposição para a solução dos conflitos servindo-se dos serviços notariais e registrais.

Desta forma, caminha em conjunto a legislação processual civil com o Provimento do Conselho Nacional de Justiça $\mathrm{n}^{\circ} 72$, dispondo sobre medidas de incentivo à quitação ou à renegociação de dívidas protestadas nos tabelionatos de protesto do Brasil. Esta é a resposta ao problema formulado, pois, em razão da análise feita, dentro do contexto dedutivo, ao ofertar ao

\footnotetext{
${ }^{24}$ BAUMAN, Zygmunt. Vida para consumo. Rio de Janeiro: Zahar, 2008. p. 12.

${ }^{25}$ ECONOMIDES, Kim. op. cit. p. 72.
} 
cidadão um meio mais rápido e célere, aceito pelo Poder Judiciário, como alternativa para a solução da controvérsia significa avanço inexorável para as partes envolvidas. É evidente que ao garantir uma nova alternativa, com amparo legal para a solução da controvérsia, importa em avanço para vencer a morosidade e tornar efetiva a prestação dos serviços, ainda mais quando delegados do serviço público.

Com a adoção dessa prática, perante os tabelionados de protestos, evidencia-se o prestigio ao "sistema multiportas" que é um instrumento hábil a ofertar respostas rápidas e eficientes para o desenvolvimento do Estado brasileiro.

\section{REFERÊNCIAS}

BAUMAN, Zygmunt. Vida para consumo. Rio de Janeiro: Zahar, 2008.

CALMON, Petrônio. Fundamentos da mediação e da conciliação, Rio de Janeiro: Forense, 2007.

CAMARGO, Rodrigo Moreira. Tabelionato de protestos: especialidade extrajudicial. Disponível em https://jus.com.br/artigos/61864/tabelionato-de-protesto, acesso em 22 de mar. 2021.

CAMPOS, Adriana Pereira. Mediação Escolar como Caminho para a Desjudicialização: Potencialidades. Argumentun, Marília, v. 19, n. 3, p. 823-844, set./dez. 2018.

CAPPELLETTI, Mauro; GARTH, Bryant. Acesso à Justiça. Tradução de Ellen Gracie Northfleet. Porto Alegre: Fabris, 1988.

CHASE, Oscar G. Direito, cultura e ritual: Sistemas de resolução de conflitos no contexto da cultura comparada. Tradução Sérgio Arenhart e Gustavo Osna. Editora Marcial Pons, São Paulo, 2014. (Coleção Processo e Direito).

DIDIER JR., Fredie; CUNHA, Leonardo Carneiro da. Julgamento de casos repetitivos. Salvador: Juspodivm, 2016.

ECONOMIDES, Kim. Lendo as ondas do "Movimento de Acesso à Justiça": epistemologia versus metodologia? In: CIDADANIA, JUSTIÇA E VIOLÊNCIA, Organizadores Dulce Pandolfi... [et al]. Rio de Janeiro: Ed. Fundação Getúlio Vargas, 1999.

GABBAY, Daniela Monteiro. Mediação \& Judiciário: Condições necessárias para a institucionalização dos meios autocompositivos de solução de conflitos. São Paulo: USP, 2011. 
GIMENEZ, Charlise Paula Colet. A Justiça Consensual do Tribunal Múltiplas Portas e a Política Pública Norte-Americana de Tratamento de Conflitos: Contribuições ao Modelo Brasileiro. In: Revista Opinião Jurídica, Fortaleza, n. 20, 2017.

GUERRERO, Luis Fernando. Efetividade das estipulações voltadas à instituição dos meios multiportas de solução de litígios. São Paulo: USP, 2012, 255 p. Tese (Doutorado) - Curso de Pós-Graduação da Faculdade de Direito da Universidade de São Paulo - Departamento de Direito Processual - DPC, São Paulo, 2012. 2012.

LEAL, Rosemiro Pereira. Teoria geral do processo: primeiros estudos. 14 ed. Belo Horizonte: Fórum, 2018.

LOUREIRO, Luiz Guilherme. Registros públicos. Rio de Janeiro: Forense; São Paulo: Método, 2014.

LUCHIARI, Valeria Feriolo Lagrasta. Histórico dos métodos alternativos de solução de conflitos. In: GROSMAN, Claudia Frankel; MANDELBAUM, Helena Gurfinkel (Org.). Mediação no judiciário: teoria na prática. São Paulo: Primavera Editorial, 2011.

NEVES, Daniel Amorim Assumpção. Manual de direito processual civil - volume único. Salvador: Juspodium, 2021.

SADEK, Maria Tereza Aina. Acesso à Justiça: um Direito e seus obstáculos. In: Revista USP, $\mathrm{n}^{\circ} 101$ (maio), 2014.

VASCONCELOS, Carlos Eduardo. Mediação de Conflitos e Práticas Restaurativas. Rio de Janeiro: Forense; São Paulo: MÉTODO, 2017.

VEZZULA, Juan Carlos. Teoria e Prática da Mediação. Curitiba: IMAB, 1998.p. 16.

WARAT, Luis Alberto. Em nome do acordo: a mediação no direito. Buenos Aires: Angra Impresiones, 1998.

ANOREG BR, 2018, on-line. Disponível em https://www.anoreg.org.br/site/, acesso em 22 de outubro de 2021. 